\title{
O melodrama como gênero jornalístico: um olhar sobre o caso Isabella Nardoni
}

Isabel Orofino

Doutora em Ciências da Comunicaşão pela Universidade de São Paulo, com pesquisa complementar na London School of Economics and Political Sciences (LSE) em Londres. Mestre em Educação e Bacharel em Comunicação Social/Jornalismo, pela Universidade Federal de Santa Catarina. É professora do Programa de Mestrado em Comunicação e Práticas de Consumo da Escola Superior de Propaganda e Marketing - PPGCOM-ESPM/SP*.

E-mail: iorofino@espm.br

Resumo: Esta crítica propõe uma reflexão sobre a dimensão da recepção no processo de midiatização do caso Isabella de Oliveira Nardoni, de cinco anos de idade, defenestrada do sexto andar do Edifício London no distrito da Vila Guilherme, em São Paulo, na noite do dia 29 de março de 2008, e no julgamento dos acusados em 22 de março de 2010, amplamente divulgado pelos meios de comunicação no espaço dedicado ao jornalismo. Analisam-se aqui as estratégias utilizadas para mobilizar as audiências a partir do uso de recursos próprios da narrativa ficcional e do gênero melodramático. Busca-se também ampliar as referências sobre a compreensão do papel dos receptores nas mediações dos conteúdos veiculados pela mídia comercial.

Palavras-chave: recepção, jornalismo, melodrama, teleficção, mediações.
Abstract: This criticism proposes a reflection about the reception dimension in the process of media coverage of the case Isabella de Oliveira Nardoni, a five year-old girl who was thrown from a sixth-story window in Edificio London, in Sao Paulo, on the night of March 29, 2008. The accuseds' trial, beginning on the 22nd of March of 2010, was widely publicized by media in the space dedicated to journalism. The strategies used to mobilize the audience through the use of fictional narrative and melodramatic genre are analyzed here. The author proposes to widen the references on the comprehension of the receptor's role in the mediations of contents carried by commercial media.

Keywords: reception, journalism, melodrama, telefiction, mediations.

A menina brasileira Isabella Nardoni de Oliveira foi encontrada mortalmente ferida, no dia 29 de março de 2008, no jardim do edifício London, após a queda de uma altura de seis andares. No apartamento, que pertencia a seu pai, moravam, além dele, a madrasta da menina e dois filhos do casal, um de onze meses e outro de três anos. A menina chegou a ser socorrida pelos bombeiros, mas não resistiu e morreu a caminho do hospital. As investigações

* Atua na linha de investigação: Impactos socioculturais da comunicação voltada para o mercado. É pesquisadora do Nica - Núcleo de Infância, Comunicação e Arte (UFSC) e do Obitel - Observatorio Iberoamericano da Ficção Televisiva (ECA/ USP). Atua na área de televisão e tecnologia nos seguintes campos: produção e recepção do audiovisual, cultura e arte, mídia e educação, educação intercultural e mediações. 
comunicação \& educação • Ano XV • número 2 • maio/ago 2010

1. SILVERSTONE, Roger. Por que estudar a mídia? São Paulo: Edições Loyola, 2002.

2. Ver a esse respeito TODA Y TERRERO, José Martínez de: AGUIRRE, Jesús Maria; CERVERA Rafael Calduch. A violência nos meios de comunicação. São Paulo: CCA-USP/Moderna. jan./ abr. 1997. O artigo faz um balanço das tendências da pesquisa de comunicação, até início da década de 1990, sobre a violência veiculada pela mass media. São pesquisas realizadas na Europa e América Latina. (N.E.). Disponível em: <http://revcom2 portcom.intercom.org. $\mathrm{br} /$ index.php/Comedu/ article/view/4324/4053>. levaram ao indiciamento do pai da menina e da madrasta, os quais tiveram a prisão preventiva decretada, decidindo a Justiça por um julgamento com júri popular em 2009. Os trabalhos no Fórum de Santana, na cidade de São Paulo, tiveram início às 14 horas do dia 22 de março de 2010 e se estenderam até a madrugada de sexta-feira, dia 26 , culminando com a condenação dos réus. Foram cinco dias de julgamento dos acusados da morte de Isabella de Oliveira Nardoni: uma maratona, uma ladainha.

Nós, telespectadores, nos tornaríamos reféns de uma cobertura jornalística minuciosa, planejada, orquestrada e ubíqua, isto é: parecia estar em todos os meios, em quase todas as horas de uma semana inteira de vida de trabalho. Ao longo daqueles dias (considerando-se que as redes de TV, sobretudo a Rede Globo, cobrem $98 \%$ do território nacional), quase toda a população do Brasil recebeu as imagens, palavras e sons de uma narrativa que muito tangencia a estrutura da telenovela. Em nosso cotidiano, na medida em que usamos a mídia para pontuar as ações da vida pessoal e familiar, é bem provável que muitos de nós tenhamos tomado o café da manhã, lavado a louça, arrumado as crianças, almoçado, preparado o jantar, enquanto acompanhávamos o discurso midiatizado das coberturas jornalísticas do caso Isabella Nardoni. Foi um episódio de comoção nacional diante da violência contra a criança, e como deveriam ser todos os casos em que elas são as vítimas, o que nem sempre se vê.

Eis aqui um momento da mídia, que, como destaca Roger Silverstone ${ }^{1}$, nos explora, mas deve ser também explorado por nós para que possamos compreendê-la a partir de sua complexidade, buscando mapear o que ela revela e o que oculta, ou aquilo que é o óbvio e o que é questionável, contraditório, fugidio.

Mas como avaliar criticamente este evento enquanto cena midiática recente? Como compreender o porquê de as empresas de comunicação do país, em sua vasta maioria, estarem presentes sem perder um detalhe sequer do que acontecia no Fórum de Santana, na capital de São Paulo? Por que pessoas deixariam as suas residências e faltariam ao trabalho para pegar uma senha na tentativa de entrar na sala do julgamento? A mídia orquestrou a multidão? Ou o caso mobilizou comunidades de receptores em busca de justiça?

É possível que não se possa responder a todas estas questões neste curto espaço de análise, porém é preciso destacar, enquanto educadores críticos, a necessidade de problematizar os eventos midiáticos para além da visão maniqueísta que vê a mídia como expressão de todo o mal e que demoniza os seus fenômenos ${ }^{2}$. Em uma busca rápida pela internet foi possível identificar uma série de críticas que denunciam os exageros das coberturas, os excessos, a capitalização da atenção dos telespectadores, a transformação da notícia em um produto à venda. Em hipótese alguma a intenção é descartar estas denúncias. Não há como pensar em comunicação social em um mundo de capitalismo global sem compreendê-la enquanto instituição imersa na lógica da produção de bens materiais e simbólicos voltados para a acumulação e maximização dos resultados (ou melhor, do lucro). A proposta é oferecer uma discussão que amplie 
o espectro da análise para além da dimensão econômica (sem desconsiderá-la) e que a problematize como uma questão de cultura.

Com isso a ideia é a defesa da hipótese de que, ao estudar a recepção para os meios e seus discursos, é essencial ampliar nossa crítica para além da leitura puramente economicista, sem desconsiderá-la, mas sim buscando trilhar os caminhos que Jesús Martín-Barbero ${ }^{3}$ nos desafiou a abrir, ou seja: aquele que presta atenção nas comunidades de recepção e nos múltiplos modos como as pessoas se apropriam das mensagens, e que explora os usos sociais que as pessoas fazem das narrativas da mídia; que indaga sobre os modos como os receptores reconhecem matrizes históricas e estruturas de sentimentos distantes e fruem e usufruem das narrativas da mídia com capacidade de ressignificá-las.

Não se trata de descartar a crítica econômica, em hipótese alguma. Mas trata-se, isto sim, de realizar um exercício de sobreposição de dimensões, de modo complexo e dialético. E muitas vezes será possível compreender que o econômico sozinho não dá conta de elucidar todas as dimensões imbricadas nos fenômenos da comunicação social midiatizada.

Dito isto, a hipótese aqui defendida é de que a cobertura policial do caso Isabella Nardoni teve tamanha repercussão não porque a mídia criou este fenômeno como algo puramente fabricado (ainda que isto esteja presente), mas porque há outras dimensões envolvendo a atividade das audiências que precisam ser consideradas.

\section{O DRAMA DA VIDA SOCIAL OU QUANDO AS ESTRUTURAS DE SENTIMENTO MOBILIZAM O PÚBLICO}

Todo texto jornalístico, de fato, conta uma história. E um jornalista é um contador de histórias ${ }^{4}$ (muitos deles frustrados, porque precisam fazer de conta que não o são) que se esconde atrás do frágil véu da objetividade. Neste sentido, as considerações de ataque ao trabalho da imprensa se devem muito mais à falácia de que o jornalismo é um espaço de objetividade, de imparcialidade, de neutralidade. No caso Isabella Nardoni, o que fica mais evidente são os interesses comerciais de ampliar uma narrativa não ficcional em vários capítulos para maximizar o potencial de exposição dos fatos e de ganho por meio dos recursos de anunciantes.

Entretanto, não é crível que os objetivos perversos do mundo capitalista mobilizariam, sozinhos, a atenção das audiências de tal modo. O caso Nardoni é interessante sob o ponto de vista da análise crítica, porque nos mostra que há muitas outras dimensões em jogo quando se trata de comunicação e cultura. Há aquela sobreposição de fatores e fenômenos que tornam a compreensão da realidade algo denso, o que leva Jesús Martín-Barbero ${ }^{5}$ a chamá-la de palimpsesto. Pois estão ali em operação as dimensões subjetivas, as memórias, as heranças em um jogo permanente entre o individual, o social e o histórico.
3. MARTÍN-BARBERO, Jesús. Dos meios às mediações: comunicação, cultura e hegemonia. Rio de Janeiro: Editora da UFRJ, 1997.

4. BACCEGA, M. A. Discurso da comunicação: encontro de ficção e realidade. Comunicação \& Educação, São Paulo: USP, v. 12, p. 23 34, 2007. Disponível em: <http://revcom.portcom. intercom.org.br/index. php/Comedu/article/ viewFile/6058/5359>.

5. MARTÍN-BARBERO, op. cit. 
comunicação \& educação • Ano XV • número 2 • maio/ago 2010

6. SANTAELLA Lúcia. Prefácio. In: VILLAÇA, Nízia. A edição do corpo: tecnociência, artes e moda. São Paulo: Estação das Letras, 2007.

7. WILLIAMS, Raymond. Culture and Society 1780-1950 (Cultura e sociedade - 1789-1950). Great Britain: Chatto and Windus, (1958) 1977.

8. SILVERSTONE, Roger. Television and everyday life (Televisão e vida cotidiana). London: Routledge, 1994
Como se a realidade fosse uma experiência tecida em muitas camadas, ou recortada em muitos ângulos, para citar a metáfora de prisma, como sugerida por Lúcia Santaella ${ }^{6}$.

Assim, uma primeira questão a considerar seria como o caso Isabella Nardoni ativou as competências culturais das audiências a partir de modos de reconhecimento em diálogo com estruturas de sentimento ${ }^{7}$, uma vez que o comentário social sobre o caso teve ressonância amplificada. Roger Silverstone, em uma análise sobre as relações entre telenovela e vida cotidiana, destaca que o melodrama atua como um coro grego $^{8}$ para o drama da vida social. O caso Isabella é um convite para pensar sobre as interfaces entre narrativa ficcional e não ficcional, telejornalismo e telenovela, e também sobre o reconhecimento do público no drama representado, como símbolo para os dramas da vida concreta de todos nós.

Nesse sentido, o melodrama atua como locus de mediação cultural, ativando as competências de reconhecimento e leitura do público na narrativa, gerando mecanismos de identificação e recusa. Com isso outro ponto é destacado: o das personagens constitutivas da trama em questão.

O processo de recepção desencadeia mecanismos de deslocamento de nossa própria posição de sujeito, enquanto telespectador, para outros posicionamentos, promovendo processos de identificação e/ou recusa em relação às personagens presentes na estruturação da narrativa. A fronteira entre o ficcional e o não ficcional é evidentemente tênue como a cobertura do caso Isabella Nardoni revela. E esses mecanismos de projeção também são responsáveis pela ampla mobilização das audiências.

Por exemplo, necessariamente há deslocamentos para o lugar da menina (e a violência doméstica contra a criança é uma das maiores crueldades da vida social, afinal a criança é geralmente impotente diante disso e impossibilitada de realizar a denúncia). Isto mobiliza um sentido de revolta e de busca por solidariedade seja a partir da memória social da infância de todo adulto telespectador, seja pela convivência com crianças em situações diversas (irmãos, filhos, alunos etc.). Outro deslocamento possível ocorre com a posição da mãe que potencialmente vai desencadear modos de reconhecimento em milhões de mães espalhadas pelo país. Evidências dessa solidariedade estiveram visíveis com a presença de mulheres adultas na porta do Fórum, inclusive a participação de Glória Perez, autora de telenovela, vítima de violência contra a própria filha, assassinada por um colega de trabalho durante as gravações de uma trama de sua autoria.

E outro deslocamento, esse gerado não por identificação, mas sim recusa: o fato de o evento ter ocorrido no cenário da vida familiar, e protagonizado pelo pai e pela madrasta, gerou mecanismos de rejeição contra a violência paterna, o que mobiliza, no sentido oposto à identificação, o desejo de distanciamento com a punição.

Já a promotoria e a perícia criminal personificam uma vontade de que no mundo exista a justiça dos homens e que seja possível viver em uma sociedade 
O melodrama como gênero jornalístico - Isabel Orofino

cujas regras impeçam a barbárie, a violência e o caos. E desse modo, todos os personagens ocupam lugares distintos que fazem o público se projetar e se reconhecer a partir de variadas posições de sujeito numa dinâmica muito mais de participação do que de alienação.

Assim, percorrendo este caminho, é possível pensar que as audiências não são meramente passivas à ação das indústrias comerciais de comunicação e suas estratégias de produção de eventos midiáticos. Mas, sim, são coadjuvantes em um diálogo social ampliado em que se tece um jogo, ora pautado pelos interesses do mercado, ora definido pelas demandas e pelos modos de reconhecimento que emergem dos diferentes sujeitos sociais. E isto não significa ser um dado de positividade em si, mas precisa também ser analisado dialeticamente. Mobilizações políticas progressistas serão sempre bem-vindas. Mobilizações pautadas pelas patologias sociais diversas, por intolerâncias e fundamentalismos serão sempre riscos de regressões das consciências históricas.

\section{QUANDO O MELODRAMA TORNA-SE GÊNERO PARA A NARRATIVA JORNALÍSTICA OU O JOGO DE ESTRATÉGIAS DA PRODUÇÃO}

Uma vez que o drama da vida social mobiliza as audiências, no caso da menina Isabella Nardoni pode-se verificar então que a narrativa jornalística perdeu completamente o seu suposto compromisso com o distanciamento, a racionalidade e a objetividade, enveredando totalmente pelos caminhos da ficção ancorada em um gênero narrativo de ampla repercussão popular: o melodrama. Nas múltiplas versões que chegavam até as audiências, tinha-se uma estrutura melodramática tal qual é possível observar em versões mais conservadoras de romances que lemos, dos filmes a que assistimos e telenovelas que vemos, e que se ancora em personagens tais como: a dor de uma mãe que perde sua filha (o bem), o casal de bandidos (o mal), o advogado do casal (a farsa), o promotor de justiça (a ordem).

Observa-se, portanto, que o telejornalismo abandona totalmente os pressupostos - que se divulgam sobre ele -, seus alicerces de base, de compromisso com o distanciamento e resvala numa cobertura oportunista que alimenta o imaginário social com capítulos e doses constantes da narrativa emocional, a qual se estende por toda uma semana, certamente com objetivos comerciais.

O outro lado da moeda, que aqui se deseja salientar, é que o público não é necessariamente ingênuo sobre tal estratégia e que, pelo bem ou pelo mal, usa tal momento da vida sociocultural para realizar um debate, um comentário sobre as regras morais e éticas da sociedade.

Ao longo de toda aquela semana foi possível observar uma cobertura exaustiva, quase massacrante, muitas vezes pautada pelo despreparo dos profissionais para agirem espontaneamente diante das situações ao vivo. Por exemplo, quando Sandra Annemberg da Rede Globo de TV pergunta 
comunicação \& educação • Ano XV • número 2 • maio/ago 2010

ao repórter César Tralli se o choro de Alexandre Nardoni, pai da vítima e acusado do crime, era verdadeiro. Enfim, o que poderia ser mais especulativo do que indagar sobre a veracidade de um choro em uma situação de total encenação? E qual a importância do choro diante das provas e evidências apontadas pela perícia criminal? Não é provável que seja mero despreparo da jornalista, mas sim a evidência de esgotamento do assunto diante da exaustiva cobertura do evento.

Em linhas gerais as narrativas jornalísticas reportaram o evento em sua linha do tempo, ampliando ao máximo a sua extensão, com objetivos comerciais, como já destacamos anteriormente. Isto o tornou um evento midiático migratório, que atravessou as fronteiras de diferentes programas e formatos televisivos. Na cidade de São Paulo, onde a cobertura foi maior por se tratar de um evento local e que contou com a cobertura da mídia existente, já nas primeiras horas da manhã o boletim de informações tratava de relatar a preparação da saída dos camburões com os acusados, especulando qual seria o trajeto das penitenciárias do interior para a Capital. Com sequências em paralelo, outra equipe dava conta de mostrar a multidão que havia dormido nas ruas e calçadas com a expectativa de conseguir uma senha para assistir ao julgamento.

O jogo narrativo oscilava entre as informações oferecidas pelo âncora no estúdio e os múltiplos recursos de entrevistas com populares, imagens aéreas acompanhando todo o percurso do comboio, reportagens sobre a menina com fotografias cobrindo textos em off (quando não se vê quem fala o texto), depoimento de especialista, vídeos de animação sobre a queda da criança do sexto andar do edifício no dia do crime, simulações etc.

Ainda a fim de manter a atenção das audiências, a produção apela para a migração da narrativa do telejornalismo, agora para o entretenimento. Já está no horário do programa Mais você, conduzido por Ana Maria Braga. Estrategicamente atentos à narrativa que se desenrola no mundo social externo, o programa mostra as imagens da entrada do pai da menina, Alexandre Nardoni, no fórum em meio aos empurrões da multidão. E então, os comentários atônitos da apresentadora: "Mas a roupa que ele está usando é de onde? Esta roupa é do presídio, não é? É um uniforme?". Nos limites do espetáculo, a apresentadora desprovida de comentários mais pertinentes parecia buscar a grife ou o estilo nos trajes usados pelo acusado a caminho do banco dos réus.

E nesta dinâmica a narrativa se estendeu, entrando e saindo de um ou outro formato comercial (do telejornalismo ao entretenimento, programa de auditório, rompendo com os horários das telenovelas), com o uso bem apropriado de um mecanismo muito familiar para os estudiosos da narrativa de ficção televisiva seriada: o gancho.

À medida de sua exploração ao máximo, em tempo real, a história do julgamento foi costurada pelos profissionais da mídia com o uso sucessivo de recursos como: "Na próxima edição, você vai acompanhar a nossa cobertura sobre o depoimento da perita judicial", ou: "Será que vai haver a acareação?", ou também: "Ainda hoje nesta edição você vai ver; não perca no jornal das onze". 
O gancho é uma estratégia comum às narrativas ficcionais e não ficcionais seriadas. É utilizado para captar a atenção do público e motivá-los a seguir com fidelidade uma dada cobertura jornalística, tanto quanto acompanhar uma narrativa de telenovela ${ }^{9}$.

No conjunto dos excessos apresentados pela mídia, no último dia, às vésperas do pronunciamento da sentença pelo juiz, a quase totalidade dos canais de televisão estava divulgando o assunto (exceto a TV Cultura de São Paulo, explicitando a diferença de política editorial, cujo discernimento merece ser elogiado e destacado).

O programa de Adriane Galisteu, por exemplo, que acontece todas as sextas-feiras na Rede Bandeirantes, pegou o filão da narrativa: o momento em que sairia a sentença do casal. Como os trabalhos no Fórum se estenderam para além do espaço do programa, a especulação era a tônica da cobertura ancorada pela ex-modelo, que em um instante parou o debate sobre o tema com um grupo de convidados especialistas para chamar o repórter de rua: "E o homem crucificado, ainda está aí?", pergunta ela ao repórter, diante da multidão que se aglomera na porta do Fórum, referindo-se a um dos inúmeros manifestantes que escolheram formas inusitadas de protesto. Ele responde: "Sim, está aqui, assim preso na cruz há 38 horas". E ela continua: "Você que está nos acompanhando, fique conosco porque, aí sim, nós vamos ficar juntos e vamos acompanhar os últimos momentos desse julgamento".

Esta é a ideia: "Fique conosco, nós vamos ficar juntos!". As estratégias da produção, incessantes, explorando o fenômeno ao máximo, com profissionais muitas vezes despreparados para coordenar um debate que mobilizou o país. Por um lado, e aqui se reitera a hipótese, tem-se uma produção de comunicação orientada para o mercado, que otimiza seus esforços evidentemente na busca por melhores resultados econômicos; que joga com estratégias e gêneros narrativos na ânsia por captar uma faixa, um share no universo quantitativo dos índices de audiência.

Do outro lado, há as comunidades de receptores presentes, onde a tal audiência quantitativa se transforma em lugares de recepção, apropriação e recusa. E daí talvez as certezas do mercado, da visão economicista e puramente racional seja desconstruída em favor de outras relações. Relações pautadas pelo respeito, pela dor da perda, pela solidariedade, pelo reconhecimento, pelo desejo de uma vida justa que toma a narrativa da menina como índice, como símbolo de uma atividade de protagonismo ético das maiorias, muitas vezes, como disse Baudrillard, silenciosas.

\section{PARA ENCERRAR}

Há uns bons vinte anos temos trabalhado com a leitura dos meios. Percebe-se que a orientação crítica continua a resvalar numa leitura um tanto mecanicista e maniqueísta do discurso da mídia comercial. Parece que é aprendida uma
9. Ver: BACCEGA, Maria Aparecida. Narrativa ficcional de televisão: encontro com os temas sociais. Comunicação \& Educação, São Paulo, n. 26, 1999. Disponível em: <http://www. revistasusp.sibi.usp.br/ scielo.php?script $=$ sci arttext\&pid = S0104 $-68291999000100002 \& \ln$ $\mathrm{g}=\mathrm{pt} \& \mathrm{nrm}=\mathrm{iso}>$. Acesso em: 23 mar. 2010; BACCEGA, Maria Aparecida; GUIMARAES, Margaret de Oliveira. Da comunicação à educação: a importância dos estudos de recepção. Comunicação \& Educação, São Paulo, v. 11, n. 3, 2006. Disponível em: <http:// www.revistasusp.sibi.usp. $\mathrm{br} / \mathrm{scielo}$.php?script=sci arttext \& pid = S0104 $-68292006000300010 \&$ ln $\mathrm{g}=\mathrm{pt} \& \mathrm{nrm}=\mathrm{iso}>$. Acesso em: 23 mar. 2010; LOPES, M. I. V.; GOMEZ, G. O. (Org.). A ficção televisiva em países ibero-americanos: narrativas, formatos e publicidade. 1. ed. São Paulo: Globo, 2009. 380 p.; LOPES, Maria Immacolata Vassallo de. Telenovela brasileira: uma narrativa sobre a nação. Comunicação \& Educação, São Paulo, n. 26, 1999. Disponível em: <http:// www.revistasusp.sibi.usp. $\mathrm{br} / \mathrm{scielo}$.php?script=sci_ arttext\&pid=S0104 $-68291999000100003 \& \ln$ $\mathrm{g}=\mathrm{pt} \& \mathrm{nrm}=\mathrm{iso}>$. Acesso em: 23 mar. 2010. 
comunicação \& educação • Ano XV • número 2 • maio/ago 2010

fórmula que ajuda a compreender a mídia como puro fenômeno de mercado que atende aos interesses ininterruptos de promoção de uma ética neoliberal, a qual reitera os valores mais conservadores da reprodução de uma sociedade capitalista desacreditada, mas que insiste em impor sua hegemonia. É claro que tudo isto prevalece no conjunto da narratividade midiática. O que se busca com esta reflexão é tentar colaborar com a divulgação de novos modos de proceder à crítica, e aqui se destaca que uma das maiores contribuições, da bibliografia que foi possível ter acesso e conhecer, advém dos estudos de recepção e mediações. Não é possível falar de mídia pressupondo sempre que as audiências sejam ignorantes, passivas, que não tenham capacidade alguma de ler ou interpretar os conteúdos veiculados, ou que sejam mera boiada teleguiada. Particularmente, a recusa é em aceitar as críticas que reiteram o caráter autômato e mecânico do que ocorre na esfera da recepção. A oportunidade de conhecer os autores dos chamados estudos culturais e todos os desdobramentos das teorias das mediações na América Latina possibilitou compreender e problematizar os fenômenos da mídia de um modo que julgamos mais difícil, porque mais complexo.

Os chamados estudos culturais são uma abordagem ou perspectiva teórico-metodológica que se insere na teoria da comunicação. Seus pressupostos epistemológicos e teóricos foram desenvolvidos no Centre for Contemporary Cultural Studies da Universidade de Birmingham, a partir dos anos 1970, sob a coordenação de Stuart Hall. De fato, as pesquisas realizadas neste centro buscaram pela primeira vez, no âmbito da teoria crítica, verificar a cotidianidade e as atividades dos receptores em relação aos discursos midiáticos. A partir daí uma ampla gama de pesquisas foi realizada em todo o mundo com preocupações voltadas aos mecanismos de resistência, leituras de oposição e recusa, reconhecimento, formação de identidades, entre outros. De modo um tanto paralelo aos estudos culturais britânicos, também a pesquisa crítica latino-americana orientou o seu foco para as atividades das audiências e os receptores. Esta perspectiva é conhecida como teorias das mediaçoes. Também em nosso continente, a partir de meados dos anos 1970, a pesquisa crítica passa a indagar sobre comunidades particulares de receptores como camponeses, classes populares, mulheres, crianças, entre outros. A América Latina possui uma trajetória rica de trabalhos que focam nesta dimensão do processo de comunicação. Dentre os autores desta perspectiva teórica destacam-se Valerio Fuenzalida, Jesús Martín-Barbero, Guillermo Orozco, Néstor García Canclini, entre outros; no Brasil, Maria Aparecida Baccega, Maria Immacolata Lopes, Nilda Jacks, entre outros.

Em hipótese alguma se deseja desconsiderar as influências sociais e históricas, ou os modos como a cultura dominante reproduz e reitera seus valores conservadores, tampouco deixar de lado a leitura crítica da constituição de monopólios da fala em uma economia política pautada pelos favorecimentos e protecionismos, muitas vezes familiares.

A proposta aqui é a reflexão sobre um fenômeno particular, amplamente veiculado pela mídia, estrategicamente explorado por suas organizações, mas 
melodrama como gênero jornalístico - Isabel Orofino

que a simples leitura das estratégias econômicas da produção pode não dar conta de explicar as múltiplas dimensões que delineiam a sua complexidade. Quando a imagem da TV chega à comunidade, seja ela um vilarejo rural, seja uma vila de pesca ou favela, as certezas do mercado se deparam com a pluralidade de experiências de vida, de contextos particulares de consumo e de leituras diferenciadas na recepção. E nós, educadores críticos, precisamos ampliar nossa capacidade de mediação ao compreender que há o outro lado da moeda (ou múltiplas facetas de um prisma) e que a esperança de localizar novos modos de apropriação, reconhecimento e resistência deveria também mobilizar a nossa atenção.

\section{REFERÊNCIAS BIBLIOGRÁFICAS}

LOPES, M. I. V.; GOMEZ, G. O. (Org.). A ficção televisiva em países ibero-americanos: narrativas, formatos e publicidade. 1. ed. São Paulo: Globo, 2009. $380 \mathrm{p}$.

MARTÍN-BARBERO, Jesús. Dos meios às mediações: comunicação, cultura e hegemonia. Rio de Janeiro: Editora da UFRJ, 1997.

SANTAELlA, Lúcia. Prefácio. In: VILLAÇA, Nízia. A edição do corpo: tecnociência, artes e moda. São Paulo: Estação das Letras, 2007.

SILVERSTONE, Roger. Por que estudar a mídia? São Paulo: Edições Loyola, 2002.

Television and everyday life (Televisão e vida cotidiana). London: Routledge, 1994.

WILLIAMS, Raymond. Culture and Society - 1780-1950 (Cultura e sociedade 1780-1950). Great Britain: Chatto and Windus, (1958) 1977.

\section{Endereços eletrônicos}

BACCEGA, M. A. Discurso da comunicação: encontro de ficção e realidade. Comunicação \& Educação, São Paulo: USP, v. 12, p. 23-34, 2007. Disponível em: $\quad<$ http://revcom.portcom.intercom.org.br/index.php/Comedu/article/ viewFile $/ 6058 / 5359>$.

. Narrativaficcionalde televisão:encontrocomos temassociais. Comunicação \& Educação, São Paulo, n. 26, 1999. Disponível em: <http:/ /www.revistasusp.sibi. usp.br/scielo.php?script=sci_arttext\&pid=S0104-68291999000100002\&lng=pt\&n rm=iso >. Acesso em: 23 mar. 2010.

BACCEGA, M. A.; GUIMARÃES, Margaret de Oliveira. Da comunicação à educação: a importância dos estudos de recepção. Comunicação \& Educação, São Paulo, v. 11, n. 3, 2006. Disponível em: <http://www.revistasusp.sibi.usp.br/ 
comunicação \& educação • Ano XV • número 2 • maio/ago 2010

scielo.php?script=sci_arttext\&pid=S0104-68292006000300010\&lng=pt\&nrm=i so>. Acesso em: 23 mar. 2010.

BACCEGA, M. A.; LOPES, Maria Immacolata Vassallo de. Telenovela brasileira: uma narrativa sobre a nação. Comunicação \& Educação, São Paulo, n. 26, 1999. Disponível em: <http://www.revistasusp.sibi.usp.br/scielo.php?script=sci_ arttext\&pid=S0104-68291999000100003\&lng=pt\&nrm=iso $>$. Acesso em: 23 mar. 2010 .

TODA Y TERRERO, José Martínez de; AGUIRRE, Jesús Maria; CERVERA, Rafael Calduch. A violência nos meios de comunicação. São Paulo: CCA-USP/Moderna, jan./abr. 1997. Disponível em: <http://revcom2.portcom.intercom.org.br/ index.php/Comedu/article/view/4324/4053>. 